\title{
Effects of physical activity on debilitating behaviours in 13- to 20-year-old males with severe autism spectrum disorder
}

\author{
Linda Duffy', Bahman Baluch ${ }^{1, *}$, Sarah Welland', Evren Raman² \\ ${ }^{1}$ School of Science and Technology, Middlesex University, London, UK \\ 2Division of Psychology, Brunel University, London, UK
}

The presented study investigated the extent to which engaging in a therapeutic sporting programme in males with severe autism spectrum disorder (ASD) improves the debilitating behaviours commonly associated with ASD. Furthermore, the views of parents of the autistic participants were assessed concerning the effectiveness of the programme. Participants were eight 13- to 20-year-old males born in the United Kingdom from a school and sports college for pupils with severe learning difficulties. The selection was using volunteer sampling from the "Monday Club" initiative, run by Saracens Sports Foundation in partnership with a local school and specialist sports college. The Gilliam Autism Rating Scale, 3rd edition was administered to identify and measure the severity of ASD behaviours at four time periods namely: at programme entry as the baseline (Time 1, T1), a second time after 8 weeks
(Time 2, T2), a third time after 16 weeks (Time 3, T3), and a fourth time post programme (Time 4, T4). The results showed that for the more severe cases of ASD (Autism Index > 101) there was no positive change in subscale performance from T1 to T2. For milder cases (Autism Index, 71-100) there were subtle non-significant improvements on the subscale scores from T1 to T2. Of the 6 subscales at T2, emotional responses, cognitive style, and maladaptive speech approached significance at the $P=0.05$ level. At T3 and T4, there was also no statistically significant improvement in ASD behaviours compared to the baseline for either condition. Finally parents' were "very satisfied" with their child's participation in the physical activity programme.

Keywords: Physical activity, Severe autism spectrum, Parents, Attitudes

\section{INTRODUCTION}

Diagnoses of autism spectrum disorder (ASD) are made on the basis that there are qualitative impairments present in three primary areas including social interaction, verbal and nonverbal communication and repetitive, restricted and/or stereotyped behavioural patterns (American Psychiatric Association, 2013) including often a morbid obsession with minutia and repetitive behaviours such as rocking, spinning, mouthing, and the need to carefully follow specific routines. Spectrum disorder refers to individuals with the diagnosis sharing common characteristics but varying considerably in severity of the way that these characteristics impact their day to day functioning (Nicholson et al., 2011), with all sharing a core deficit in forming relationships and com- municating (Kusch and Petermann, 1997; Pratt et al., 2001). Diagnosing and treating this wide variability of characteristics is further complicated by the frequent presence of comorbid physical and psychological disorders and symptoms including hyperactivity, attention difficulties, seizure disorder and depression (Bellini, 2004). One of the prominent characteristics of ASD is difficulties with social interactions (Sowa and Meulenbroek, 2012) which results from an impaired ability to relate, interpret and communicate with other people in social situations. ASD conditions are considered to be an important public health consideration, causing high service utilisation (Järbrink et al., 2003) due to their early onset, persistence throughout the lifetime, associated impairment, and absence of effective treatment for core problems (Simonoff et al., 2008).
${ }^{*}$ Corresponding author: Bahman Baluch (iD http://orcid.org/0000-0003-0650-4421 School of Science and Technology, Middlesex University, The Burroughs, London NW4 4BT, United Kingdom

Tel: +44-20-8411-5000, Fax: Fax: +44-20-8411-5343, E-mail: b.baluch@mdx.ac.uk Received: April 13, 2017 / Accepted: June 10, 2017
This is an Open Access article distributed under the terms of the Creative Commons Attribution Non-Commercial License (http://creativecommons.org/licenses/by-nc/4.0/) which permits unrestricted non-commercial use, distribution, and reproduction in any medium, provided the original work is properly cited. 
When examining interventions for children with ASD, to date it is the behaviourally based interventions that have been found to be the most effective (Schreibman, 2000) which focus on developing communication, social and cognitive skills, with communication skills crucial for learning and establishing connections with others (Bahrami et al., 2016). Several past investigations have shown that, in particular, physical activity based interventions are effective in addressing various symptoms associated with children's ASD diagnosis (Nicholson et al., 2011). This is concurrent with findings that improvements in correct responding, academic interest and decreases in "out of seat" behaviour in children with autism were associated with contingent jogging routines (Gordon et al., 1986; Kern et al., 1982).

It has been suggested that the youth population with ASD could be at risk of inactivity due to the social and behavioural deficits often associated with their condition (Pan and Frey, 2006) and these deficits may limit opportunities for participation in physical activity, team and social games (Fox and Riddoch, 2000). Children diagnosed with ASD have been observed to engage less in physical activity than their peers and therefore typically have poorer physical fitness (Auxter et al., 1997) and low levels of physical activity coupled with high levels of sedentary behaviours may contribute to harmful health outcomes (Jones et al., 2017). This emphasises the importance of physical activity based interventions, not just for improving self-esteem, behaviour, happiness and social outcomes (Biddle et al., 1998; Strauss et al., 2001), but as a productive way of treating and improving characteristics of ASD. Existing research in the area has demonstrated that aerobic exercise may lead to the reduction of aggressive behaviour (Allison et al., 1991; Gabler-Halle et al.; 1993; Yell, 1988) and reduce stereotyped and self-injurious behaviour (Bachman and Fuqua, 1983; Baumeister and MacLean, 1984; Elliot et al., 1994; Petrus et al., 2008; Prupas and Reid, 2001). In addition, there have been decreases in self-stimulatory behaviours associated with autism following planned physical activity (Rosenthal-Malek and Mitchell, 1997) and decreasing levels of communication related deficits following physical exercise in the form of karate training (Bahrami at al., 2016). While research is fairly established into behavioural interventions, physical activity has also been shown to improve cognitive health across the human lifespan, with aerobic fitness in particular enhancing cognitive strategies such as greater attentional focus which enables an individual to respond to a challenge with more successful results (Gomez-Pinilla and Hillman, 2013). Exercise has also been demonstrated to improve executive functioning which is central to cognitive development in children by increasing brain volume in areas implicated in this, leading to improved attention and performance (Ploughman, 2008; Tomporowski et al., 2008). In particular, research has indicated that aerobic physical activity has positive effects on cognition and brain function (Hillman et al., 2008), can stimulate neurogenesis and improve learning and mental performance (Cotman and Berchtold, 2002) and improve gross motor function in children and adolescents with developmental disabilities (Johnson, 2009).

Research has demonstrated that parents of children with ASD express concern for their involvement in physical activity as they see negative societal attitudes from people in the community towards ASD children as a barrier to participation (Khader and Pehlivan, 2016). The most frequently reported barriers to after-school physical activity of children with ASD were reported by parents to be community, interpersonal and intrapersonal related (Obrusnikova and Miccinello, 2012) and this was echoed by Askari et al. (2015) who stated that negative social attitudes are critical as an important environmental barrier to the participation in out-ofschool activity. Furthermore, parents themselves have to overcome barriers caused by the characteristics of their child's disability, including behavioural, motor, attention and social deficits (Khader and Pehlivan, 2016). Perceived advantages of after-school physical activity were reported to include physical, psychosocial and cognitive benefits (Obrusnikova and Miccinello, 2012), demonstrating that parents express approval for the positive outcomes of their child participating in physical activity. The reported opinion of parents is that the ideal form of physical activity for their child's ASD is that which suits their child's needs best, as ASD represents a spectrum of abilities, needs and preferences (Khader and Pehlivan, 2016).

Research into effective interventions for ASD has given reason to suggest that a physical exercise intervention programme, focusing on communication, social and cognitive skills will be beneficial in treating children exhibiting severe characteristics of ASD as exercise appears an effective strategy to counteract neurological and cognitive disorders (Gomez-Pinilla and Hillman, 2013) and thus may be a simple yet important method of enhancing aspects of children's mental functioning (Tomporowski et al., 2008) as it can stimulate neurogenesis and improve learning and mental performance (Cotman and Berchtold, 2002). In particular, aerobic exercise has been demonstrated to reduce maladaptive and stereotypic behaviours (Elliott et al., 1994) and have positive effects on cognition and brain function (Hillman et al., 2008), in addition to increasing attention and performance on cognitive tasks by increasing brain volume in areas implicated in executive processing 
(Ploughman, 2008). Exercise programmes within a group setting specifically have also been demonstrated to improve gross motor function in children and adolescents with developmental disabilities (Johnson, 2009). The physical exercise intervention programme addresses both the need for increased activity in individuals with ASD and promotes pro-social values, confidence and self-esteem which contribute to positive outcomes and improved quality of life.

The present study is aimed at investigating the benefits of physical activity, in particular engaging in the Saracens Foundation "Monday Club" therapeutic sporting programme and examining if there is a significant improvement in the severity of debilitating behaviours and characteristics commonly associated with ASD. Furthermore, to assess parents' perspectives of their autistic child's participation with physical activity.

It is anticipated that there will be an improvement of social skills, self-esteem and reduction of self-stimulating behaviours common amongst individuals with ASD as a result of consistent weekly physical exercise, in addition to the improvement of communication skills, anxiety and obsessive behaviours which is of particular focus. In view of the concerns of the parents of autistic children regarding their participation in physical activity, due to social stigma towards autistic children it would be of importance to see how they rate their satisfaction with the current intervention programme.

\section{MATERIALS AND METHODS}

\section{Participants}

The statistical population of this study were 13 - to 20-year-old males referring to the "Monday Club" initiative, run collaboratively by Saracens Sports Foundation in partnership with a school and specialist sports college in the London borough of Barnet for pupils between 2-20 years old with severe learning difficulties. Eight participants were selected using volunteer sampling from the statistical population, with their parents who attended the club with them approached to participate on a voluntary basis.

A pretest posttest within participant design was employed in which the main independent variable was the time of assessment at four levels. The main dependent variables were the responses to the Gilliam Autism Rating Scale, 3rd edition (GARS-3) (Gilliam, 2003). A questionnaire was also administered to parents of participants at the end of the programme to measure parent satisfaction with the programme itself, and their child's progress.

\section{Materials and procedure}

Ethical approval for the study was granted by the Middlesex University Ethics Committee and the Saracens Foundation. Consent was gained, firstly by establishing contact with the parents of prospective participants in the first session of "Monday Club" at Saracens' facility at Allianz Park. They were invited to take part in the study and written permission was obtained prior to the commencement of data collection. Parents completed a brief child/adolescent background questionnaire designed specifically for the study, with the motive of collecting background information regarding the child and their parents.

All participants were tested using this background questionnaire and the GARS-3. When evaluating interventions working as much variability in symptoms as there is in ASD, there is a need to use standard reliable and valid tools (Scharoun et al., 2014). The GARS-3 is one of the most widely used instruments for the assessment of ASD, consisting of 56 items describing characteristic behaviours of individuals with autism. The items are grouped into 6 subscales: restrictive, repetitive behaviours (RB), social interaction (SI), social communication, emotional responses (ER), cognitive style (CS), and maladaptive speech (MS). Participants who were reported as mute were measured using the 4 subscale form as opposed to the 6 subscale form. The parent satisfaction questionnaire was administered at the conclusion of the programme, with parents responding to 19 statements regarding the programme itself, and their perceptions of their child's progress, with statements including "The classes provided opportunities for social interaction with other children" and "After participating in the programme, my child's endurance (ability to participate in movement activities for longer periods) improved". The response scale ranged from 1 = strongly agree, 2 =agree, 3 = neutral, 4 = disagree, $5=$ strongly disagree.

The 6 months "Monday Club" programme consists of two hour weekly sessions. Each participant was assessed four times on the GARS-3 scale, once at programme entry to serve as the baseline (T1), a second time after 8 weeks (T2), a third time after sixteen weeks (T3) and a fourth time post programme (T4).

\section{RESULTS}

It is necessary to mention that participant coded as 08 was excluded from the GARS-3 data due to lack of participation in the programme, so the data could not be used for meaningful comparison. However, the participant's parent was present at the sessions, so their data from the parent satisfaction questionnaire was 
Table 1. Results of paired samples t-test on pre and post assessment periods in the present study

\begin{tabular}{lccc}
\hline Scale & $t$ & $d f$ & Sig. (2-tailed) \\
\hline Index & 0.454 & 7 & 0.664 \\
Repetitive behaviours & 0.261 & 7 & 0.802 \\
Social interaction & -1.166 & 7 & 0.282 \\
Social communication & -1.000 & 7 & 0.351 \\
Emotional response & 2.049 & 7 & 0.08 \\
Cognitive style & -2.042 & 7 & 0.08 \\
Maladaptive speech & -2.054 & 7 & 0.079 \\
\hline
\end{tabular}

Table 2. Mean overall autism index score for each assessment period (T1-T4)

\begin{tabular}{lcccc}
\hline & \multicolumn{4}{c}{ Mean autism index score } \\
\cline { 2 - 5 } & Time 1 & Time 2 & Time 3 & Time 4 \\
\hline $\begin{array}{l}\text { Mean score for cohort } \\
\text { on GARS-3 }\end{array}$ & 100.38 & 99.88 & 99.25 & 97.78 \\
\hline
\end{tabular}

T1, Time 1, baseline; T2, Time 2, second time after 8 weeks; T3, Time 3, third time after 16 weeks; T4, Time 4, fourth time post programme; GARS-3, Gilliam Autism Rating Scale, 3rd edition.

used to compare against the other parents views whose children had fully participated in the physical activity sessions.

The difference between $\mathrm{T} 1$ and $\mathrm{T} 2$ testing showed a subtle improvement in that scores of ASD related behaviours decreased. Formal analysis of the data using a paired samples $t$-test was conducted to determine if there was a statistically significant improvement, but this was not demonstrated to be significant $t$ $(7)=0.45, P=0.66$.

However, changes in the ER, CS, and MS subscales of the GARS- 3 instrument approached significance at the $P=0.05$ level as seen in Table 1.

The difference between baseline and T3 and T4 testing showed a slight improvement, but less so than the improvement demonstrated when comparing $\mathrm{T} 2$ and $\mathrm{T} 1$ and it was not demonstrated to be statistically significant for either $\mathrm{T} 3, t(7)=1.38, P=0.22$ or $\mathrm{T} 4, t(7)=1.18, P=0.28$. Comparing severe cases (Autism index $>101$ ) and milder cases (Autism index, 71-100) also indicated a difference, with no positive change in subscale scores for the most severe cases, but subtle nonsignificant changes in subscale scores for milder cases, there were changes observed in RB, SI, and ER across participants in addition to CS for nonmute participants.

Overall as can be seen in Tables 2 and 3, most participants showed a maintenance or reduction in their overall autism index score over the duration of the programme, in addition, a similar pattern found for Restricted/Repetitive Behaviours (Table 4) and Emotional Responses (Table 5). This demonstrates a trend to-
Table 3. Mean overall autism index score for each participant at each assessment period (T1-T4)

\begin{tabular}{lrccc}
\hline \multirow{2}{*}{ Participant (code) } & \multicolumn{4}{c}{ Mean autism index score } \\
\cline { 2 - 5 } & Time 1 & Time 2 & Time 3 & Time 4 \\
\hline 1 & 87 & 81 & 80 & 74 \\
2 & 109 & 114 & 114 & 119 \\
3 & 108 & 108 & 103 & 108 \\
4 & 93 & 90 & 86 & 87 \\
5 & 125 & 125 & 125 & 123 \\
6 & 99 & 99 & 97 & 90 \\
7 & 89 & 89 & 89 & 86 \\
\hline
\end{tabular}

T1, Time 1, baseline; T2, Time 2, second time after 8 weeks; T3, Time 3, third time after 16 weeks; T4, Time 4, fourth time post programme.

Table 4. Mean score for restrictive, repetitive behaviours subscale for each participant at each assessment period (T1-T4)

\begin{tabular}{lcccc}
\hline \multirow{2}{*}{ Participant (code) } & \multicolumn{4}{c}{ Mean score } \\
\cline { 2 - 5 } & Time 1 & Time 2 & Time 3 & Time 4 \\
\hline 1 & 12 & 9 & 8 & 7 \\
2 & 26 & 27 & 29 & 30 \\
3 & 25 & 26 & 26 & 26 \\
4 & 22 & 23 & 15 & 14 \\
5 & 39 & 39 & 39 & 39 \\
6 & 21 & 20 & 20 & 17 \\
7 & 12 & 12 & 10 & 8 \\
\hline
\end{tabular}

T1, Time 1, baseline; T2, Time 2, second time after 8 weeks; T3, Time 3, third time after 16 weeks; T4, Time 4, fourth time post programme.

Table 5. Mean score for emotional responses subscale for each participant at each assessment period (T1-T4)

\begin{tabular}{lcccc}
\hline \multirow{2}{*}{ Participant (code) } & \multicolumn{4}{c}{ Mean score } \\
\cline { 2 - 5 } & Time 1 & Time 2 & Time 3 & Time 4 \\
\hline 1 & 18 & 15 & 12 & 9 \\
2 & 18 & 19 & 20 & 23 \\
3 & 23 & 21 & 20 & 23 \\
4 & 8 & 5 & 3 & 2 \\
5 & 24 & 24 & 24 & 24 \\
6 & 14 & 12 & 11 & 9 \\
7 & 16 & 16 & 16 & 14 \\
\hline
\end{tabular}

T1, Time 1, baseline; T2, Time 2, second time after 8 weeks; T3, Time 3, third time after 16 weeks; 74 , Time 4, fourth time post programme.

wards a lower or equal score on the GARS-3 over the four assessment periods throughout the programme.

As can be seen in Table 6, displaying the mean overall scores for each parent on the parent satisfaction questionnaire administered at the conclusion of the programme, most parent responses remained under the mean score of 2 meaning they mostly agreed or 
Table 6. Mean overall response score for each participant's parent who completed the parent satisfaction questionnaire at the culmination of the present study

\begin{tabular}{lc}
\hline Parents of participants (code) & Mean questionnaire response score \\
\hline 01 & 2.11 \\
02 & 1.67 \\
03 & 1.44 \\
04 & 1.83 \\
05 & 1.17 \\
06 & 1.00 \\
07 & 1.00 \\
08 & 2.33 \\
\hline
\end{tabular}

strongly agreed with every statement. The parent of participant 08 provided the worst mean overall score of 2.33 .

The best scoring statements were Q6, Q7, Q8, Q9, and Q10 which had a mean response of 1.25 - meaning the majority of parents had responded with 'strongly agree.' These statements were: Q6, The exercise class was a good length of time for my child; Q7, The class instructors created a fun atmosphere where my child felt motivated to participate; $\mathrm{Q} 8$, The class instructors provided my child with sufficient instructions and assistance; Q9, The class instructors had the appropriate knowledge and expertise to work with my child; Q10, The class instructors were responsive to my suggestions.

The worst scoring statements were Q17 and Q18 which had a mean response of 2, meaning that parents had mostly responded with 'strongly agree', 'agree' or 'neutral'. These statements were: Q17, After participating in the exercise programme, my child's ability to participate with a group of children improved; Q18, After participating in the exercise programme, my child's communication skills improved.

The overall question of "how would you rate your satisfaction with the exercise programme?" on a scale of $1=$ very satisfied, $2=$ satisfied, $3=$ neutral, $4=$ dissatisfied, $5=$ very dissatisfied had a mean response of 1.13 , indicating that overall, parents were "very satisfied" with their child's participation in the programme.

\section{DISCUSSION}

The aim of the present study was to examine the effectiveness of engaging in a therapeutic sporting programme in males with severe ASD. Results showed that there was no significant improvement of behaviour subscales throughout the course of the programme compared to the baseline score, however some of the subscales of the GARS-3 measure approached significance from T1 to
T2. This indicates that starting the programme had the potential for improvements in ER, CS, and MS. There were minor improvements observed in T3 and T4, but not enough to state for certain that the "Monday Club" initiative is successful alone in improving the debilitating behaviours characteristic of ASD, replicating findings that no single intervention has been proven to be beneficial in alleviating the fundamental symptoms of ASD (Sandler et al., 2001). The only data approaching significance is the comparison between $\mathrm{T} 1$ and $\mathrm{T} 2$, indicating that the starting point and days immediately after the initiative may be when the intervention has the most impact, reinforcing research that acute sessions of physical activity have short-term benefits on behaviour and cognitive functioning in youths struggling to focus attention and control impulsive actions (Tomporowski, 2003). The week-long gap between each exercise class could allow the behaviours and characteristics displayed by the children to maintain at their level rather than improve, as there is tremendous variability in ASD (Howlin, 1998).

Overall, of the participants who provided complete data and with one exception, there was a maintenance or reduction in ASD behaviours throughout the lifetime of the initiative. This demonstrates that the Saracens sporting programme went some way to improving the stereotypical behaviours of participants with ASD, and for the most part, also maintained them at a level, indicating stability. This pattern was also seen for RB and ER, indicating that perhaps these subscales were the most stable and susceptible to improvement through physical activity, and would benefit from being explored further in future research as focal points of potentially successful intervention programmes.

There was also an indication from the results of this study that the physical activity had a greater improvement with less severe cases of ASD (as measured on the autism index at 71-100) and this reiterates previous findings that cognitive ability in children with autism correlates with the outcome of therapy intervention (Ben-Itzchak and Zachor, 2007), with higher initial ability (i.e., less severe impairments) linked to more positive outcomes in acquisition of skills in developmental areas. It would be beneficial to carry out further research into this area using a neuro typical control group of participants who do not attend the weekly "Monday Club" sessions, to compare the scores of physical activity between the two groups (Memari et al., 2015) and to further test the GARS-3 measure which has shown to be sensitive to changes in ASD severity over time.

Effective ASD intervention programmes need the approval and participation of parents of child participants to thrive, as previous research has demonstrated that the family plays a large and essen- 
tial role in increasing or decreasing their ASD child's participation in physical activity (Khader and Pehlivan, 2016) and that attention needs to be also focused on parental and peer support. The present study showed that the parents expressed approval for the structure, atmosphere and instructor presence of the exercise classes, with the lack of trainers able to provide physical activity services for ASD children acknowledged in research as a key issue and barrier to participation (Khader and Pehlivan, 2016) and the importance of empathy and disability awareness training for people involved in the child's physical activity emphasised (Obrusnikova and Miccinello, 2012). The instructors at the "Monday Club" initiative were stated to have created a fun atmosphere where children felt motivated, provided sufficient instructions and assistance, have possessed appropriate knowledge and expertise, in addition to being responsive to parent suggestions. This is a positive outcome to the evaluation of the programme, as the beliefs and perceptions of parents alongside their support for physical activity plays a vital role in the development of children's health-related behaviour (Baranowski, 1997; Sallis et al., 2000). The structure, recognition and opportunities for continued participation and skill development has been acknowledged by parents as important in increasing physical activity levels (Obrusnikova and Miccinello, 2012) and the establishing of schedules and routines related to the physical activity is also considered to be important in providing ASD children with opportunities to participate. In particular, the worst scoring parent on the satisfaction questionnaire in the present study was the parent of Participant 08, who did not participate within the sports classes, however the parent was present at the sessions so they completed the questionnaire. This is of note because it draws upon one of the study's aims of assessing parents' perspectives relating to the concern they express for their autistic child's participation in physical activity due to perceived social and practical barriers. The reason for the parent's worse score may have been because their child did not participate in a lot of activities on offer at the sessions, and thus they may not have experienced the perceived improvements or benefits that some of the other parents based their ratings on. This is of interest for future research, as it indicates that it may be the direct witnessing of their ASD child's participation in beneficial physical activity that improves parent satisfaction and therefore their motivation for involving their children in such programmes. Overall, whilst parents were initially sceptical about the programme and how it would help their autistic child, they expressed satisfaction when surveyed at the programme's conclusion about how it had engaged and benefited their child's behaviours.
The aspects of the programme that parents were less positive about were the improvements to communication skills, which could inform the need for improving the programme in addition to existing interventions in this area. The worse score of Parent 08 may have also had an impact on the two worst scoring statements, as they were specifically concerning participation in group settings and communication skills, and would have been difficult to observe in their child due to their limited participation with the group session. However, the development of a weekly out-of-school programme such as this one already contributes to the issue acknowledged by parents in previous research that there are not enough programmes in their community providing support and activity for their child's particular and unique needs (Khader and Pehlivan, 2016; Obrusnikova and Miccinello, 2012). Parents responding to the present study seemed to agree with the notion that children with ASD could potentially benefit from lifestyle modifications that promote increased physical activity (Jones et al., 2017).

It is worth noting that the sample used in this study was small, and it has been recommended that a larger sample size is used to find out whether similar findings will result from studies on autism (Bahrami et al., 2016) and it is essential to ensure samples are sufficient to provide meaningful results (Jones et al., 2017). The sample in the present study also included a large participant age range (8-20 years old) due to its small size. Despite the limited sample size, the present study demonstrated a trend in the right direction, with a small positive improvement in scores despite the small sample, and with further investigation and a larger sample size more significant results would be expected. Jones et al. (2017) recommended that future studies in this area should include a power calculation to ensure researchers recruit a sufficiently sized sample to enable identification of associations and thus provide meaningful results, in addition to focusing on a narrower age range where children are at the same or similar developmental stage and exposed to similar environments. In terms of bias, there may have been a minor amount of recall bias, since measures relied on parents' and observers' self-report information (Memari et al., 2015), however the GARS-3 instrument is designed to be completed by parents or caregivers. If it was possible, taking into account the severity of some of the participants' ASD, future research could benefit from additionally investigating the perspectives of the children with ASD themselves, through interviews or video observation of their interaction with the physical activity programme.

To conclude, it has been demonstrated in research into intervention programmes designed for those with ASD that physical activity programmes have benefits for participants including im- 
proved endurance, confidence, balance ability and gross motor skills (Ploughman, 2008; Tomporowski et al., 2008) and thus can be recommended to be used in conjunction with additional conventional behavioural therapies to improve the quality of life of an individual with ASD. Initiatives and programmes within the community would also benefit from recognising that ASD children require their programmes to be flexible and adjustable as necessary, as they often have a range of challenges which makes their involvement in physical activity difficult (Khader and Pehlivan, 2016). This study, alongside other recent research including the Jones et al. (2017) review demonstrate potential correlates in physical environment which remain largely unexamined, and future research would benefit from exploring this further with a larger sample, investigating correlates for different age groups and both genders to help inform future effective interventions.

\section{CONFLICT OF INTEREST}

No potential conflict of interest relevant to this article was reported.

\section{ACKNOWLEDGMENTS}

This work was funded by Saracens Rugby Football Club Sport Foundation. The authors are grateful to Natasha Bernberg for her assistance with data collection.

\section{REFERENCES}

Allison DB, Basile VC, MacDonald RB. Brief report: comparative effects of antecedent exercise and lorazepam on the aggressive behavior of an autistic man. J Autism Dev Disord 1991;21:89-94.

American Psychiatric Association. Diagnostic and statistical manual of mental disorders. 5th edition. Washington, DC: American Psychiatric Association; 2013.

Askari S, Anaby D, Bergthorson M, Majnemer A, Elsabbagh M, Zwaigenbaum L. Participation of children and youth with autism spectrum disorder: a scoping review. Rev J Autism Dev Disord 2015;2:103-114.

Auxter D, Pyfer J, Huettig C. Principles and methods of adapted physical education and recreation. Boston: McGraw-Hill; 1997.

Bachman JE, Fuqua RW. Management of inappropriate behaviors of trainable mentally impaired students using antecedent exercise. J Appl Behav Anal 1983;16:477-484.

Bahrami F, Movahedi A, Marandi SM, Sorensen C. The effect of karate techniques training on communication deficit of children with autism spectrum disorders. J Autism Dev Disord 2016;46:978-986.

Baranowski T. Families and health actions. In: Gochman DS, editor, Handbook of health behavior research I: Personal and social determinants. New York: Plenum Press; 1997. p. 179-206

Baumeister AA, MacLean WE Jr. Deceleration of self-injurious and stereotypic responding by exercise. Appl Res Ment Retard 1984;5:385393.

Bellini S. Social skill deficits and anxiety in high-functioning adolescents with autism spectrum disorders. Focus Autism Other Dev Disabil 2004;19:78-86.

Ben-Itzchak E, Zachor DA. The effects of intellectual functioning and autism severity on outcome of early behavioral intervention for children with autism. Res Dev Disabil 2007;28:287-303.

Biddle SJ, Sallis JF, Cavill N. Young and active? Young people and health-enhancing physical activity - evidence and implications. London: Health Education Authority; 1998.

Cotman CW, Berchtold NC. Exercise: a behavioral intervention to enhance brain health and plasticity. Trends Neurosci 2002;25:295-301.

Elliott RO Jr, Dobbin AR, Rose GD, Soper HV. Vigorous, aerobic exercise versus general motor training activities: effects on maladaptive and stereotypic behaviors of adults with both autism and mental retardation. J Autism Dev Disord 1994;24:565-576.

Fox KR, Riddoch C. Charting the physical activity patterns of contemporary children and adolescents. Proc Nutr Soc 2000;59:497-504.

Gabler-Halle D, Halle JW, Chung YB. The effects of aerobic exercise on psychological and behavioral variables of individuals with developmental disabilities: a critical review. Res Dev Disabil 1993;14:359-386.

Gilliam JE. GARS: Gilliam autism rating scale: valutazione diagnostica per i disturbi dell'autismo: manuale dell'esaminatore. 3rd ed. Torino: Omega Edizioni; 2003.

Gomez-Pinilla F, Hillman C. The influence of exercise on cognitive abilities. Compr Physiol 2013;3:403-428.

Gordon R, Handleman JS, Harris SL. The effects of contingent versus non-contingent running on the out-of-seat behavior of an autistic boy. Child Fam Behav Ther 1986;8:37-44.

Hillman CH, Erickson KI, Kramer AF. Be smart, exercise your heart: exercise effects on brain and cognition. Nat Rev Neurosci 2008;9:58-65.

Howlin P. Practitioner review: psychological and educational treatments for autism. J Child Psychol Psychiatry 1998;39:307-322.

Järbrink K, Fombonne E, Knapp M. Measuring the parental, service and cost impacts of children with autistic spectrum disorder: a pilot study. J Autism Dev Disord 2003;33:395-402.

Johnson CC. The benefits of physical activity for youth with developmental disabilities: a systematic review. Am J Health Promot 2009;23:157167. 
Jones RA, Downing K, Rinehart NJ, Barnett LM, May T, McGillivray JA, Papadopoulos NV, Skouteris H, Timperio A, Hinkley T. Physical activity, sedentary behavior and their correlates in children with autism spectrum disorder: a systematic review. PLoS One 2017;12:e0172482.

Kern L, Koegel RL, Dyer K, Blew PA, Fenton LR. The effects of physical exercise on self-stimulation and appropriate responding in autistic children. J Autism Dev Disord 1982;12:399-419.

Khader W, Pehlivan A. Parent perceptions of barriers to physical activity for children with autism spectrum disorders. Swed J Sci Res 2016;3:1218.

Kusch M, Petermann F. Pervasive developmental disorders. In: Essau. CA, Petermann F, editors. Developmental psychopathology: epidemiology, diagnostics and treatment. Amsterdam: Harwood Academic Publishers; 1997. p. 177-218.

Memari AH, Panahi N, Ranjbar E, Moshayedi P, Shafiei M, Kordi R, Ziaee V. Children with Autism Spectrum Disorder and Patterns of Participation in Daily Physical and Play Activities. Neurol Res Int 2015; 2015:531906.

Nicholson H, Kehle TJ, Bray MA, Heest JV. The effects of antecedent physical activity on the academic engagement of children with autism spectrum disorder. Psychol Sch 2011;48:198-213.

Obrusnikova I, Miccinello DL. Parent perceptions of factors influencing after-school physical activity of children with autism spectrum disorders. Adapt Phys Activ Q 2012;29:63-80.

Pan CY, Frey GC. Physical activity patterns in youth with autism spectrum disorders. J Autism Dev Disord 2006;36:597-606.

Petrus C, Adamson SR, Block L, Einarson SJ, Sharifnejad M, Harris SR. Effects of exercise interventions on stereotypic behaviours in children with autism spectrum disorder. Physiother Can 2008;60:134-145.

Ploughman M. Exercise is brain food: the effects of physical activity on cognitive function. Dev Neurorehabil 2008;11:236-240.

Pratt CL, Vicker BA, Davis K. Early intervention for young children with autism spectrum disorders: Recommendations for designing effective programs. Bloomington (ID): Indiana Resource Center for Autism, Indiana Institute on Disability and Community, Indiana University;
2001.

Prupas A, Reid G. Effects of exercise frequency on stereotypic behaviors of children with developmental disabilities. Educ Train Ment Retard Dev Disabil 2001;36:196-206.

Rosenthal-Malek A, Mitchell S. Brief report: the effects of exercise on the self-stimulatory behaviors and positive responding of adolescents with autism. J Autism Dev Disord 1997;27:193-202.

Sallis JF, Prochaska JJ, Taylor WC. A review of correlates of physical activity of children and adolescents. Med Sci Sports Exerc 2000;32:963-975.

Sandler AD, Brazdziunas D, Cooley WC, González de Pijem L, Hirsch D, Kastner TA, Kummer ME, Quint RD, Ruppert ES. Counselling families who choose complementary and alternative medicine for their child with chronic illness or disability. Pediatrics 2001;107,3:598-601.

Scharoun SM, Reinders NJ, Bryden PJ, Fletcher PC. Dance/movement therapy as an intervention for children with autism spectrum disorders. Am J Dance Ther 2014;36:209-228.

Schreibman L. Intensive behavioral/psychoeducational treatments for autism: research needs and future directions. J Autism Dev Disord 2000; 30:373-378

Simonoff E, Pickles A, Charman T, Chandler S, Loucas T, Baird G. Psychiatric disorders in children with autism spectrum disorders: prevalence, comorbidity, and associated factors in a population-derived sample. J Am Acad Child Adolesc Psychiatry 2008;47:921-929.

Sowa M, Meulenbroek R. Effects of physical exercise on autism spectrum disorders: a meta-analysis. Res Autism Spectr Disord 2012;6:46-57.

Strauss RS, Rodzilsky D, Burack G, Colin M. Psychosocial correlates of physical activity in healthy children. Arch Pediatr Adolesc Med 2001; 155:897-902.

Tomporowski PD. Cognitive and behavioral responses to acute exercise in youths: a review. Pediatr Exerc Sci 2003;15:348-359.

Tomporowski PD, Davis CL, Miller PH, Naglieri JA. Exercise and children's intelligence, cognition, and academic achievement. Educ Psychol Rev 2008;20:111-131.

Yell ML. The effects of jogging on the rates of selected target behaviors of behaviorally disordered students. Behav Disord 1988;13:273-279. 